\title{
Providing Frequency Support of Hydro-Pumped Storage to Taiwan Power System with Wind Power Integration
}

\author{
Yuan-Kang Wu*, G. W. Chang, Bo-Yu Hsiao, Li-Tso Chang \\ Department of Electrical Engineering, National Chung-Cheng University, Taiwan \\ Email: "allenwu@ccu.edu.tw
}

Received 29 February 2016; accepted 10 April 2016; published 13 April 2016

Copyright $(\subset 2016$ by authors and Scientific Research Publishing Inc.

This work is licensed under the Creative Commons Attribution International License (CC BY). http://creativecommons.org/licenses/by/4.0/

\section{(c) (i) Open Access}

\begin{abstract}
The combination of wind and pumped storage is a useful method to compensate the fluctuation of wind power generation, which would exploit the abundant wind potential and increase wind power penetration. Taiwan Power Company (TPC) develops renewable energy actively in recent years. Moreover, TPC has started planning a high penetration wind power system and building offshore wind farms around the coast of Zhangbin, Yunlin and Penghu. The target of the offshore wind power installed capacity is up to $3 \mathrm{GW}$ by 2025 . However, the integration of the large scale of wind power would give huge challenges to the system operator because wind is randomly characterized. In this study, after high penetration wind power is integrated, the impacts of system frequency and the dispatch of conventional units will be discussed. Additionally, the hybrid system combing wind power with pumped-storage will be planning to reduce the effect of system frequency.
\end{abstract}

\section{Keywords}

High Penetration Wind Power, Large-Scale Offshore Wind Farm, Pumped-Storage, Hybrid System

\section{Introduction}

Since the interest in wind power installations has been increased with the new demand for clean and sustainable energy sources, more and more renewable energy is integrated into the power system. In the future, many wind power plants will be installed and the wind energy penetration in Taiwan would be up to $20 \%$ by 2030 . The large scale of wind farm will inevitably encounter greater disturbances from wind that is characterized by ran-

${ }^{*}$ Corresponding author. 
dom. Wind fluctuation is a key factor influencing both the quality and stability of a wind farm's power supply. In power systems, the total generation must be continuously adjusted to match with the demand. The stochastic nature of wind makes the active power of system fluctuate severely, which greatly increases the difficulties in adjusting the grid system frequency. Large wind penetration requires fast increased regulating power, and the spinning reserves must be closely related to and nearly proportional to the output of the wind generation system. This requirement is expected to increase the cost of the necessary ancillary services. Many issues about the wind power integration are related directly to the penetration level of wind power; it is essential to have a commonly definition term. In this work, the instantaneous wind power penetration is defined as the ratio of the plant output to load at a specific point in time, or over a short period of time [1]. References [2] [3] aim to present in a thorough and coherent way the picture redrawn for electric power systems under large wind power penetration. Topics related to technical challenges emerged and relevant technical solutions required are analyzed, and the impact on transient and frequency stability for a power system at very high wind penetration is described. In [4], with high wind power penetration, conventional power plants are displaced and wind speed fluctuations introduce large power imbalances which lead to power system frequency control and operational problems.

In the recent years the combined use of wind and storage capabilities has started receiving attention. For example, an automatic load shedding scheme considering the pumped-storage units at Taiwan Power Company (Tai power) is proposed in reference [5]. It presents that the Tai power owns ten pumped-storage units which can be shed with higher priority when operated in pumping mode in order to restore the system frequency. In reference [6], the introduction of energy storage is considered as the most effective means to remove obstacles to significantly increase wind penetration levels in electric power systems, particularly in the case of isolated island grids. In this study, an operating policy is proposed for hybrid wind-hydro power stations (HPSs) in island grids, to increase wind penetration levels, while at the same time minimizing the impact on the conventional generation system and ensuring the viability of the HPS investment. Reference [7] discusses application of Automatic Generation Control to wind power farms. Proper control schemes are developed to manage the imbalance. Wind power represents a variable energy source. Hence unpredictable wind variations may contribute to the imbalance, and should therefore be included in the control schemes. In reference [8], the introduction of the up spinning reserve (USR) is the reserve capacity for a sudden load increase, unpredictable fall in wind turbine generator power output, or forced outage of thermal generators. The down spinning reserve (DSR) is the reserve capacity designed for sudden load decreases and unpredictable increases in wind turbine generator power output. Reference [9] reports on the first offshore wind farm to be planned in Taiwan and will have a significant role in the development of renewable energy in this country. In traditional unit commitment problems with wind power, tradition thermal units have to be scheduled frequently in order to satisfy the fluctuation of both load and wind power output. When pumped hydro-energy storage is integrated, the grid security and operating economy can be greatly improved. In [10], a unit commitment problem with wind power and pumped storage was studied by using binary particle swarm optimization algorithm. The following section will introduce some significant literature reviews for hybrid wind-pumped systems, especially for several real cases on islands and the optimization problem on the hybrid wind-pumped systems.

\section{Literature Review}

There are many hybrid wind-pumped systems in the world. For instance, the Gran Canaria Island with 20.7 MW of wind power was regulated through the installation of a 16 MW seawater-based pumped hydro storage system, in which a reversible pumped hydro system facility that uses seawater is located on the Gran Canaria Island [11]. The experience about the wind and pumped hydro storage systems in Greek islands was studied in [12], and the results show that the development cost of the wind-pumped hybrid system is competitive to the fuel cost of local power stations in Greek islands. The Hybrid Power Station of Ikaria Island in Greece with an operating policy is introduced in [13]; however, the dynamic response and regulation issues are not dealt with in [13]. Turkey is a suitable country to develop hybrid wind-pumped storage systems because Central Black Sea coast is the most suitable region to built wind-hydro pumped storage systems due to the mountains lie parallel to the coast, black sea region is rainy all seasons and it is the rainiest region in the whole of Turkey. Therefore, [14] investigated the hydropower and wind energy potential in Turkey, and the contribution of wind-hydro pumped storage systems could meet Turkey's electric energy demand. [15] investigated a wind powered pumped storage system for the non-interconnected islands of Karpathos and Kasos, in which seawater is utilized as the lower reservoir; fur- 
thermore, the dimensioning, the sitting and the economic evaluation of the proposed wind powered pumped storage system have been studied.

Many researches have discussed about the optimization problem to maximize the wind park profit in the operation of the wind-hydro system. For example, the technical and economic sizing of a wind-hydropower plant has been studied in many works using AI or other algorithms to simulate the daily or yearly operation of the plant. [16] presented a numerical study of the optimum sizing and design of a pumping station unit in a hybrid wind-hydro plant, in which three different pumping station configurations are considered: identical and constant speed pumps, combination of constant-speed and small jockey pumps, and variable-speed pumps. Its target is to maximize the normalized Net Present Value of the investment. [17] proposed an optimization approach to help identifying the best strategy for the operation of a combined wind-hydro pumping storage power plant, in which the hourly operation of the wind-pumped storage and mini hydrogenerator is determined. [18] determined the optimal sizing of the hybrid system's components (hydro turbines, pumps, wind farm, reservoirs) to maximize the return on the system investment, or the optimization target is the maximization of renewable energy penetration. The optimization applied the genetic algorithms. [19] calculated the best operation of a storage plant to maximize the revenue in the conventional operation of the storage plant and to offer a reserve to a wind power producer for managing the power imbalances, in which the required reserve depends on the accuracy of the wind power forecasts.

\section{Descriptions of Taiwan Power System}

This works uses 2015 Taiwan off-peak power system for the research. Taiwan power system is a north-to-south transmission structure; it can be divided into northern, central and southern areas, which uses $345 \mathrm{kV}$ transmission line for main power delivery. The detailed power supply capability in Tai power system is shown in Table 1. The total installed capacity of power generation is around 40,247 MW, in which pumped hydro power accounts $6.5 \%$ and other renewable power generation only accounts $0.9 \%$. However, during the peak-load hours, renewable energy contributes less power; i.e., around $0.1 \%$ because renewable energy cannot provide stable power output.

\subsection{Overview of Pumped-Storage Power Plant in Taiwan System}

At high penetration levels, volatility of wind power production could cause problems for power systems to maintain system security and reliability. One solution is to use electrical energy storage. Generally, pumpedstorage is the most extensively utilized form of electrical energy storage and has been use for many decades. The

Table 1. Power supply capacity in Tai power system.

\begin{tabular}{|c|c|c|c|c|}
\hline & \multicolumn{2}{|c|}{ Installed capacity } & \multicolumn{2}{|c|}{ Net peak capacity } \\
\hline & MW & $\%$ & MW & $\%$ \\
\hline Pump hydro power & 2602 & 6.5 & 2392 & 5.9 \\
\hline \multicolumn{5}{|c|}{ Renewable energy } \\
\hline Hydro power & 1937 & 4.8 & 1312 & 3.3 \\
\hline Others & 370 & 0.9 & 22 & 0.1 \\
\hline Subtotal & 2307 & 5.7 & 1334 & 3.3 \\
\hline \multicolumn{5}{|c|}{ Thermal power } \\
\hline Coal-fired power & 11,897 & 29.6 & 11,146 & 27.7 \\
\hline Fuel-fired power & 3610 & 9.0 & 3449 & 8.6 \\
\hline Gas-fired power & 14,687 & 36.5 & 14,295 & 35.5 \\
\hline Subtotal & 30,194 & 75.0 & 28,891 & 71.8 \\
\hline Nuclear power & 5144 & 12.8 & 4955 & 12.3 \\
\hline Total & 40,247 & 100 & 3571 & 93.3 \\
\hline
\end{tabular}


Ming-tan and Da-guan 2 pumped-storage hydro power plants in Taiwan have operated since 1984, and the total installed capacity reached 2602 MW. Traditionally, the main applications of pumped-storage hydro power plants in Taiwan include peak load shifting, spinning reserve of the system, system frequency adjustment, under-frequency load shedding in water pumping mode.

\subsection{The Planning of Wind Power and Pumped-Storage Hybrid System}

TPC plans to integrate large scale of wind power to the grid in next few decades. It will be a feasible solution to coordinate with the wind power and pumped hydro storage system, which called "wind power and pumped-storage hybrid power supply system”. In the simulations, the pumped storage system is no longer be only used as a part of load shedding schedule; instead, it will have additional functions.

\subsection{Up Spinning Reserves and Down Spinning Reserves}

Most of the electric units must be able to accommodate the loss of the largest generator in the system with limited power flow and frequency variation. Typically, the spinning reserve is defined as the generation capacity that is on-line but unloaded or low load that can respond to compensate for generation or transmission outages.

Up Spinning Reserve (USR) is the reserve capacity for a sudden load increases, unpredictable fall in wind turbine power output, or forced outage of generators. It is closely related to and nearly proportional to the output of the wind generation system. The USR is generally supplied by hydro power units. As the wind turbine output decreases, more generation units must be turned on to supply the incremental USR requirement. Down spinning reserve (DSR) is the reserve capacity designed for sudden load decreases and unpredictable increases in the power output of wind turbine generators. It is designed to compensate for fluctuation in wind turbine power output. The DSR can be supplied by pumped storage systems or by cutting off some generation units. It is not a good choice to turn off thermal units to supply the additional down reserve caused by the wind farm increments. Therefore, it is necessary to coordinate the USR and DSR when operating power systems with large scale of wind power integration [8].

\subsection{System Frequency Control}

The standard frequency in Taiwan power system is $60 \mathrm{~Hz}$, and the variability of system frequency is controlled in the range between $60.1 \mathrm{~Hz}$ and $59.9 \mathrm{~Hz}$. The grid frequency is the basic indication of the system power balance between generation and load. The frequency will drop when the load is greater than the power generation and rise when the power generation is greater than the load. Currently, frequency control in Taiwan is divided into three methods:

- Primary control: Primary control is more commonly known as Frequency Response. Frequency response occurs within the first few seconds following a change in system frequency (disturbance) to stabilize the interconnection.

- Supplementary control: The most common means of exercising secondary control is through Automatic generation control (AGC) and Emergency generation control (EGC). The EGC is applied to modify the system frequency immediately after AGC control.

- Under frequency load shedding (UFLS): As frequency drops, motors will turn slower and draw less energy. Rapid reduction of system load may also be affected by automatic operation of under-frequency relays which interrupt pre-defined loads within fractions of seconds.

\section{Impacts of High Wind Power Penetration on Taiwan Power System}

The development of wind power in Taiwan would rely heavily on large-scale offshore wind farm constructions. For example, if the total installed capacity of wind farms in Taiwan is $2733.86 \mathrm{MW}$, it would account for about $12 \%$ of the off-peak load. Here, we assume the penetration of wind power is $6 \%, 12 \%, 15 \%$, and $18 \%$ respectively and the detailed information is listed in Table 2. In this work, it will be aimed at the influence of large amount of wind farms on voltage and frequency in Taiwan power system.

\subsection{Fluctuating Wind Power Coordinates with Under-Frequency Load Shedding Scheme}

Under-frequency load shedding is performed in order to minimize the risk of an uncontrolled system separation, 
Table 2. System load and power plants under various wind power penetration.

\begin{tabular}{ccccc}
\hline Wind power penetration & $6 \%$ & $12 \%$ & $15 \%$ & 21,720 \\
Total load (MW) & 21,720 & 21,720 & 21,720 & $18 \%$ \\
Conventional generator outputs (MW without loss) & 20,366 & 18,996 & 2724 & 3287 \\
Wind farm outputs (MW) & 1354 & 4064 \\
\hline
\end{tabular}

loss of generation, or system shutdown. In the cases of high penetration wind power integration, the wind variation may cause the load shedding from the system. If sufficient load is shed to preserve interconnections and keep generators online, the system can probably be restored. The present Tai power owns ten pumped storage units that can be shed with higher priority in order to restore the system frequency. The under-frequency load shedding scheme in Taiwan is shown in Table 3.

Here, the pumped storage system is assumed to pump water at full load. The power output of wind farms is decreased due to a sudden drop in wind speed, and then the under frequency load shedding scheme can be used to coordinate with the decline in wind power output. In the simulation, it is assumed that wind velocity decreases from a mean value of $14 \mathrm{~m} / \mathrm{s}$ to $7 \mathrm{~m} / \mathrm{s}$ between $1 \mathrm{~s}$ and $10 \mathrm{~s}$. The Tai power owns ten pumped storage units which can be shed with higher priority in order to restore the system frequency. This simulation case mainly adjusts the system frequency through the load shedding scheme as wind speed drops.

In these cases of high wind power penetration, the wind farm will generate in the initial state of simulation. When the wind speed falls, the power output of wind farm is decreased. Moreover, when the system frequency is lower than the predetermined shedding frequency, the Ming-tan and Da-guan unit pumping load will be shed.

The power output of the high penetration wind farms will decrease due to a sudden drop in wind speed. In this work, it is assumed that wind velocity decreases from a mean value of $14 \mathrm{~m} / \mathrm{s}$ to $7 \mathrm{~m} / \mathrm{s}$ between $1 \mathrm{~s}$ and $10 \mathrm{~s}$. The simulation results of load shedding as wind speed drops are shown in Table 4. For example, in the case of 6\% penetration, the initial wind power generation is 1353.6 MW. When the wind speed falls, the power output of wind farm decreased from 1353.6 MW to 355 MW. Moreover, the Ming-tan unit 1 and Da-guan unit 1 pumping load shed immediately when the system frequency is lower than the first step of the shedding frequency. Because the first step load has been shed, the system frequency will be maintained at $59.56 \mathrm{~Hz}$ and stop decline.

When the wind power penetration level is high, the pumping load would be shed as the wind drops. However, even though all the pumping loads have been shed, such shedding capacity is still insufficient to restore the system frequency to a normal value. More importantly, the under frequency load shedding schemes is an emergency measure when the system loses large amounts of power. Furthermore, the number of shedding steps is too difficult to coordinate with rapidly change of the wind power output, and it can easily lead to a situation of excessive or insufficient load shedding. Therefore, we will discard the existing under frequency load shedding schemes and then coordinate the wind power and pumped-storage system in the next section.

\subsection{Fluctuating Wind Power Compensated by Wind Power and Pumped-Storage Hybrid System}

The initial conditions in Taiwan high penetration power system are summarized in Table 4. The conventional power plants are set as base-load power plants, and the hydro power plants can be operated at half load, which can provide up and down spinning reserves as shown in Table 5. In the simulation, it is assumed that wind velocity increases from $7 \mathrm{~m} / \mathrm{s}$ to $14 \mathrm{~m} / \mathrm{s}$. After large-scale wind power integration, the hybrid power supply system will regulate the power output to deal with the wind fluctuation of wind power instantaneously.

In these cases of high wind power penetration, the wind farm generates on low wind speed at the initial state of simulation. When the wind speed rises, the power output of wind farm is increased to the rated output of wind farm. Then, the pumped storage system operates in water pumping mode, which absorbs the excess electricity generated from wind power. Furthermore, the hydro power plants reduce their outputs to maintain the balance between supply and demand.

Figure 1 shows the system frequency for four cases. Based on the simulation results, it is emphasized that the pumped-storage and hydro power units have their limits. Therefore, if this energy cannot quickly be adjusted, it will cause significantly frequency fluctuation and result in dramatically damage on the system. The peak value of system frequency is shown in Table 6. We may find the system frequency fluctuates dramatically under circumstances of fixed spinning reserve. It is very difficult to maintain the frequency at the desired interval. 


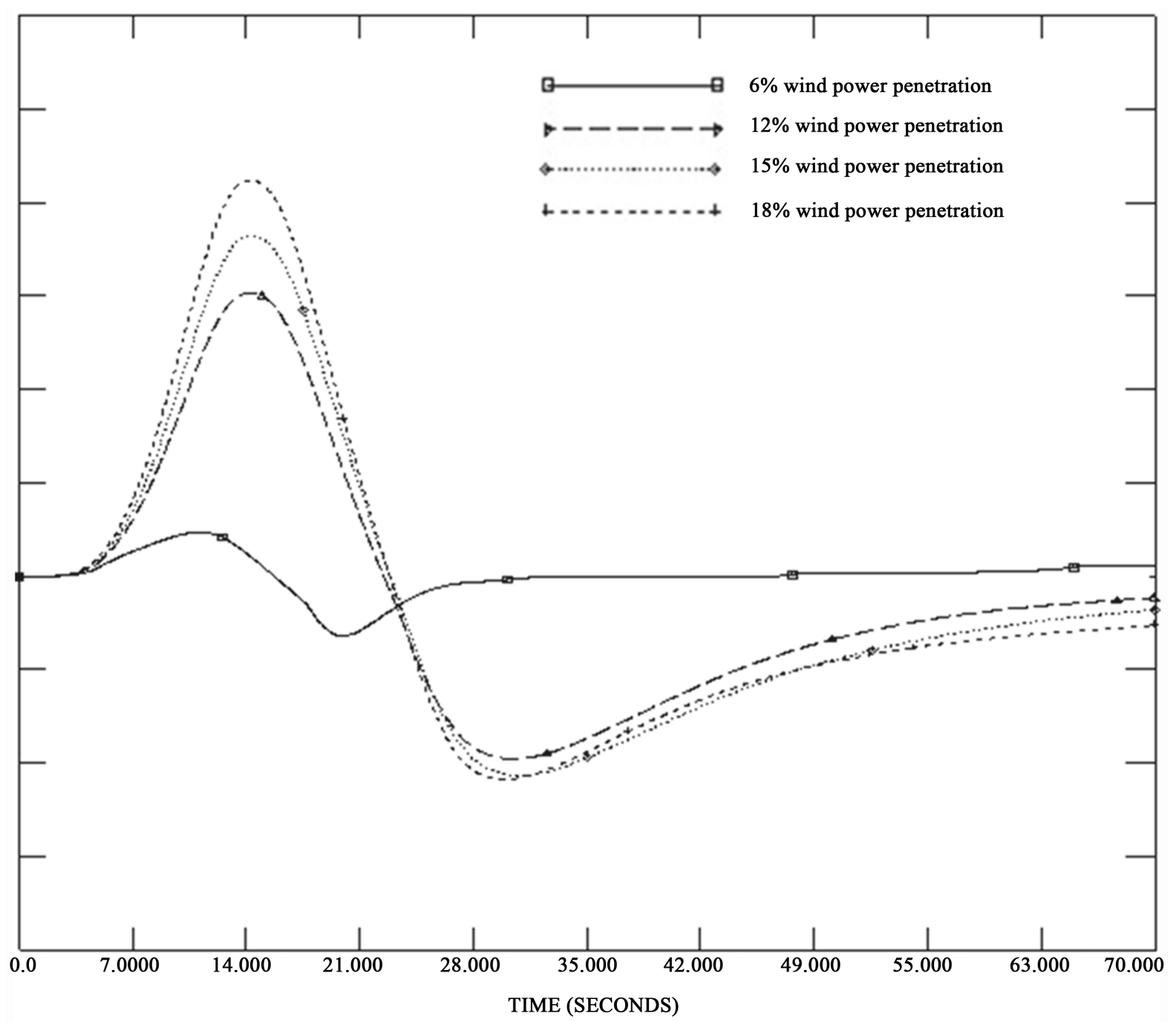

Figure 1. The system frequency variation of all cases.

Table 3. Load shedding schedule in Taiwan.

\begin{tabular}{|c|c|c|c|}
\hline \multicolumn{4}{|c|}{ Shedding schedule of pumped storage system } \\
\hline Segment & Trigger point $(\mathrm{Hz})$ & Trigger time (s) & The shedding number of units \\
\hline 1 & 59.5 & Instantaneous & $\begin{array}{l}\text { Da-guan } 2 \text { Unit } 1 \\
\text { Ming-tan Unit } 1\end{array}$ \\
\hline 2 & 59.35 & Instantaneous & $\begin{array}{l}\text { Da-guan } 2 \text { Unit } 2 \\
\text { Ming-tan Unit } 2\end{array}$ \\
\hline 3 & 59.24 & Instantaneous & Da-guan 2 Unit 3 \\
\hline 4 & 59.25 & $3 \mathrm{~s}$ & Da-guan 2 Unit 4 \\
\hline $4 \mathrm{~A}$ & 59.5 & $15 \mathrm{~s}$ & Ming-tan Unit 3 \\
\hline $4 \mathrm{~B}$ & 59.5 & $30 \mathrm{~s}$ & Ming-tan Unit 4 \\
\hline 4C & 59.5 & $45 \mathrm{~s}$ & Ming-tan Unit 5 \\
\hline $4 \mathrm{D}$ & 59.5 & $60 \mathrm{~s}$ & Ming-tan Unit 6 \\
\hline \multicolumn{4}{|c|}{ Shedding schedule of local load (Trigger point at $59.2 \mathrm{~Hz}$ ) } \\
\hline
\end{tabular}


Table 4. Simulation results of all cases.

\begin{tabular}{ccccc}
\hline Wind power penetration & $\mathbf{6 \%}$ & $\mathbf{1 2 \%}$ & $\mathbf{1 5 \%}$ & $\mathbf{1 8 \%}$ \\
\hline Rated power output of wind farms (MW) & 1353.6 & 2724.23 & 3286.8 & 4064 \\
Power output of wind farm at low load (MW) & 355.5 & 725 & 865 & 1065 \\
Amount of load shedding (MW) & 480 & 1440 & 1920 & 2160 \\
Stage of load shedding & 1 & $1,2,3,4 \mathrm{~A}$ & $1,2,3,4,4 \mathrm{~A}, 4 \mathrm{~B}$ & $1,2,34,4 \mathrm{~A}, 4 \mathrm{~B}, 4 \mathrm{C}$ \\
System frequency after load shed (Hz) & 59.56 & 59.56 & 59.64 & 59.19 \\
\hline
\end{tabular}

Table 5. Generation data under different wind penetration scenarios.

\begin{tabular}{|c|c|c|c|c|}
\hline Wind power penetration & $6 \%$ & $12 \%$ & $15 \%$ & $18 \%$ \\
\hline Off peak Taiwan system loads (MW) & 21,720 & 21,720 & 21,720 & 21,720 \\
\hline Up spinning reserve (MW) & 2440 & 2440 & 2440 & 2440 \\
\hline Down spinning reserve (MW) & 2790 & 2790 & 2790 & 2790 \\
\hline Hydropower plant capacity & 430 & 430 & 430 & 430 \\
\hline Pumped storage plant capacity & 2400 & 2400 & 2400 & 2400 \\
\hline Power generation of conventional unit & 21,867 & 21,148 & 21,014 & 20,802 \\
\hline Rated output of wind farm & 1353.6 & 2724.23 & 3286.8 & 4064 \\
\hline Output of wind farm on low wind speed & 355.5 & 725 & 865 & 1065 \\
\hline
\end{tabular}

Table 6. Peak value of system frequency.

\begin{tabular}{|c|c|c|c|c|c|}
\hline \multicolumn{2}{|c|}{ Wind Power Penetration } & $6 \%$ & $12 \%$ & $15 \%$ & $18 \%$ \\
\hline \multirow{2}{*}{ Spinning reserve (MW) } & Up spinning reserve & 2595 & 2595 & 2595 & 2595 \\
\hline & Down spinning reserve & 2635 & 2635 & 2635 & 2635 \\
\hline \multirow{2}{*}{ Wind gust (Hz) } & The highest frequency value & 60.12 & 60.75 & 60.91 & 61.06 \\
\hline & The lowest frequency value & 59.84 & 59.51 & 59.47 & 59.45 \\
\hline
\end{tabular}

\subsection{Maximum Penetration Rate of Wind Power in Taiwan}

In the previous section, the wind power and pumped-storage hybrid system with four wind power penetration levels in Taiwan power system was discussed, in which the hydropower, pumped storage system and wind farm are regulated dynamically with the variation in power output. However, the range of frequency fluctuation is far beyond the regular operation range $(59.9 \mathrm{~Hz}-60.1 \mathrm{~Hz})$ of Tai power Company. It is not permitted to operate in this situation. Therefore, we will find out the maximum limit of wind power penetration while the current Taiwan power system is coordinated with pumped-storage and hydropower plants. From the simulation results, we find the $6 \%$ penetration system has the minimal effect on the frequency. Therefore, we will attempt to curtail several offshore wind farms in case of $6 \%$ penetration system, and try to investigate the maximum limit of wind power penetration in Taiwan by considering the Tai power operation standard. In the simulation, it is assumed that wind velocity increases from $7 \mathrm{~m} / \mathrm{s}$ to $14 \mathrm{~m} / \mathrm{s}$. The Zhangbin, Penghu and Yunlin offshore wind farms will be curtailed, in which the total wind power output decreases from 1350 MW to 591 MW. The criterion for determining the maximum penetration is that the system frequency must be varied between 59.9 and $60.1 \mathrm{~Hz}$.

Figure 2 shows that the system frequency variation after wind speed changes, in which several wind farms are curtailed. It is obviously that the system is much stable after the large scale wind farms have been curtailed, and the real power variation in the system due to wind variation would be much smaller. From the simulation results in Figure 2, we may find that wind farms have been curtailed because the numbers of hydro and pumped 


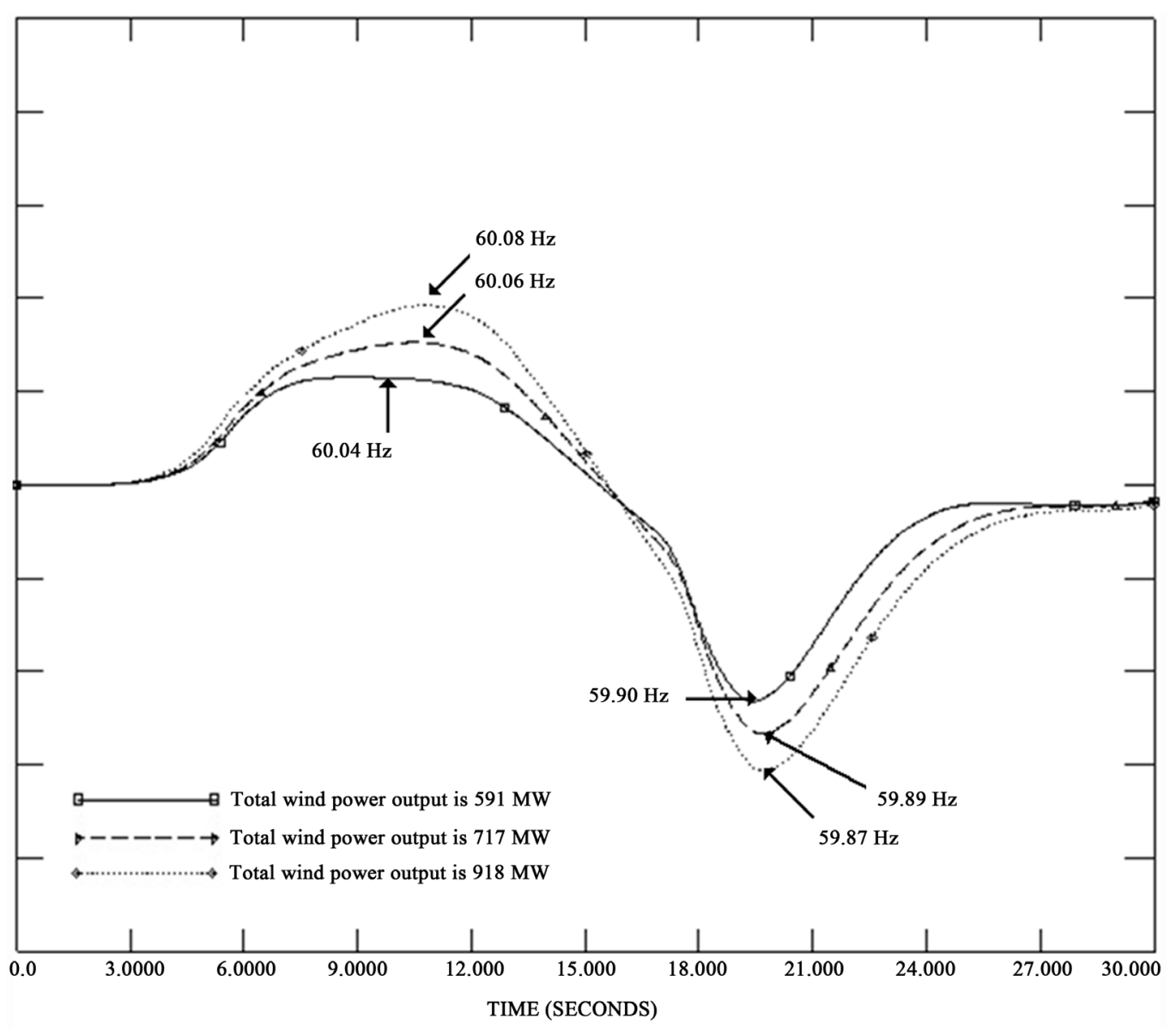

Figure 2. System frequencies after wind variation.

storage units are limited as the USR and DSR and their ramp-rate characteristics are restricted, which only remained 591 MW of wind power penetration.

In other words, if we only use the present units in Taiwan power system, then it is difficult to reach the penetration levels to $6 \%, 12 \%, 15 \%, 18 \%$ or higher. It is a huge challenge to use large scale wind power because we may need more fast-response energy storage devices and more thermal generation units that have fast ramp-up and ramp-down rates to compensate the wind power fluctuation quickly. In this section, we try to find out the maximum limit of wind power penetration in Taiwan power system, in which the system frequency must control at the operation range $(59.9 \mathrm{~Hz}-60.1 \mathrm{~Hz})$.

\subsection{Improvements on the Maximum Wind Power Penetration in Taiwan}

Based on the previous results, the maximum wind power penetration of Tai power system is around 500 - 600 MW installation capacity. Therefore, the simulation in this section is focused on the strategy how to achieve the $6 \%, 12 \%, 15 \%$ and $18 \%$ wind power penetration. After large-scale wind farm integration, it might need the energy storage system with large capacity and rapid response; the pumped storage system is the best solution undoubtedly. Therefore, the additional pumped storage and hydropower units are considered. The planning of additional units is divided into three levels. The numbers of pumped storage and hydropower units will be added based on the first, second, and third level. For each level, it increases one pumped storage unit and doubles the hydropower capacity at a level.

Here, it is assumed that original and additional pumped storage units are connected to the grid and operate in turbine mode. Wind speed variation is a usual case; the system must have the ability to withstand the continuous real power changes. Additionally, it is more important to maintain the frequency within the standard value issued by Tai power operation specification, i.e., 60.1 - 59.9 Hz. 
The use of hydropower, pumped storage system and wind power system with a rated power above $1350 \mathrm{MW}$ (6\% penetration) are regulated dynamically with the variation in power output. The most important is the observation on system frequency. Moreover, it must be determined if the hydro or pumped units should be increased or not, so that the system frequency can be maintained within the standard value of Tai power operation.

Figure 3 shows that system frequency of the Tai power system. It indicates that frequency fluctuation is still obvious during wind speed variation, even only original pumped storage and hydropower units are operated. The maximum and minimum value of the system transient frequency with original units is $60.12 \mathrm{~Hz}$ and $59.84 \mathrm{~Hz}$ respectively; the maximum and minimum value of the system frequency with the first level additional units is $60.10 \mathrm{~Hz}$ and $59.86 \mathrm{~Hz}$ respectively. These two cases are unable to maintain the frequency value between 60.1 $\mathrm{Hz}$ and $59.9 \mathrm{~Hz}$.

After the system is integrated more pumped storage and hydropower units, such as the cases of the second and third levels of additional units, the USR (up spinning reserve) and DSR (down spinning reserve) have to be increased accordingly; then, the system can be stronger and faster enough to against the great losses for wind energy. The frequency fluctuations will become smaller after the additional hydro or pumped storage units are integrated. According to the simulation results (Table 7), it seems that the system frequency becomes more and more stable, from the first level to the third level. However, the output of power generation is limited by the ramp rate of the units. Therefore, it is necessary to raise the amount of the hydro or pumped storage units in order to achieve a higher wind power penetration.

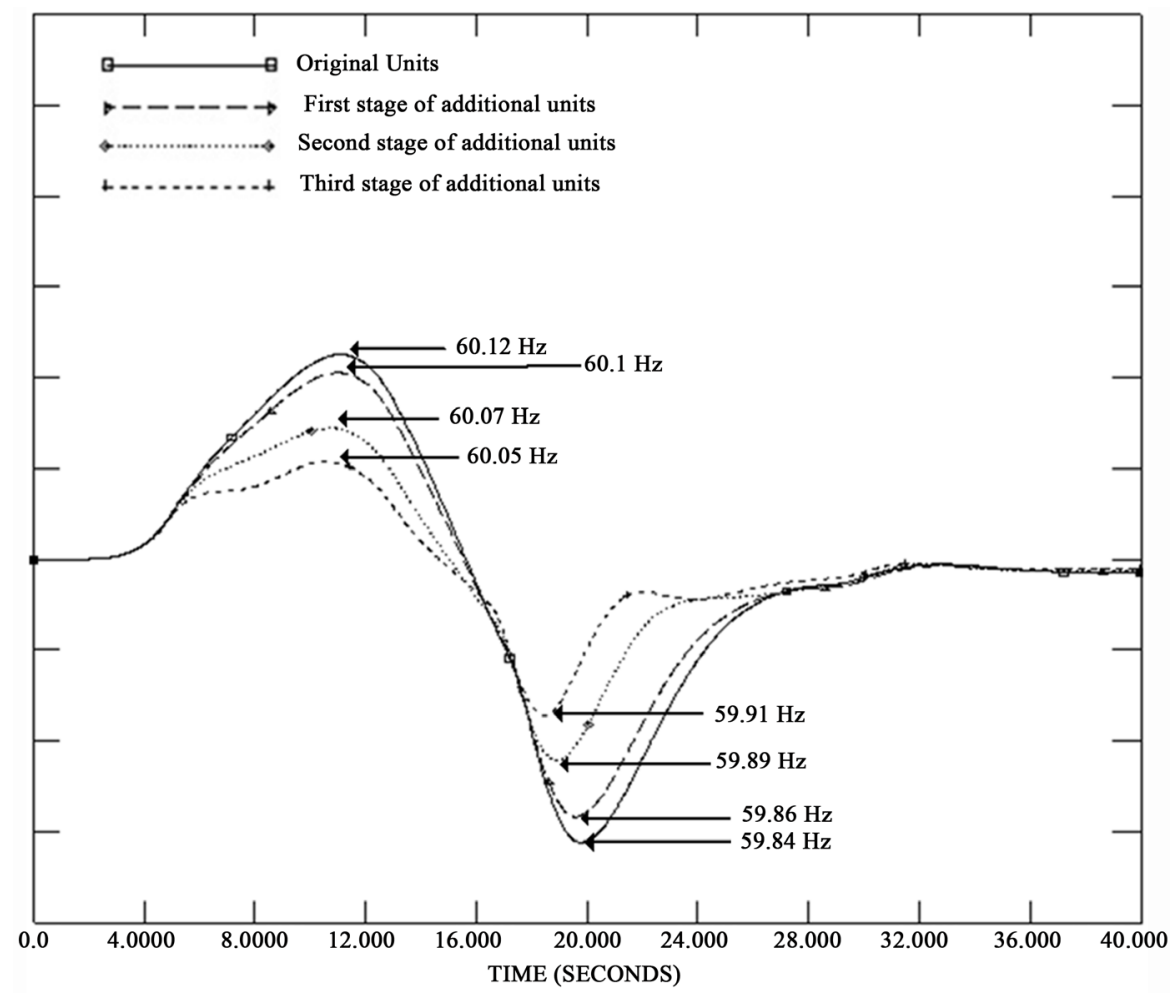

Figure 3. The system frequency variation under different additional units (wind power is above $1350 \mathrm{MW}$ ).

Table 7. Frequency values of four additional unit levels.

\begin{tabular}{ccccc}
\hline \multicolumn{5}{c}{ Total installed capacity $1350 \mathrm{MW}$} \\
\hline & USR (MW) & DSR (MW) & Highest Freq (Hz) & Lowest Freq (Hz) \\
\hline Original & 2440 & 2790 & 60.12 & 59.84 \\
First & 2810 & 3330 & 60.10 & 59.86 \\
Second & 3180 & 3870 & 60.07 & 59.89 \\
Third & 3550 & 4410 & 60.05 & 59.91 \\
\hline
\end{tabular}




\section{Conclusion}

This paper discusses the impacts of large scale wind power installation and focuses on the coordination of the generating units in the present Tai power system. First of all, four large-scale offshore wind farms are planned, and then the high wind penetration system is coordinated with two kinds of regulation strategies: the under-frequency load shedding and the hybrid system combining wind power with pumped-storage system. The former is used by Tai Power Company currently and the later has been proposed by many countries for developing their wind power. As high penetration wind power is integration, the wind speed variation would cause the load shedding from the system, but the number of shedding levels is too difficult to coordinate with rapidly change of the wind power output. In contrast, the use of hydropower, pumped storage system and wind farms can regulate with the variation on power outputs rapidly. However, the amounts of hydropower and pumped storage units may be limited and the ramp-up rate of hydropower units could not keep up with the great power change from large scale wind farms, which would cause significant fluctuation to the frequency and the restriction of wind power development in Taiwan. Therefore, we would need more fast-response energy storage devices and generation units with fast ramp-up and ramp-down rates to regulate the power fluctuation quickly.

\section{Acknowledgements}

This work is financially supported by 105-3113-E-194-001-CC2. Project title: Development of Integration Technology for Large-Scale Offshore Wind Farms in Taiwan (3/3).

\section{References}

[1] Pezeshki, H., Wolfs, P.J. and Johnson, M. (2011) Multi-Agent Systems for Modeling High Penetration Photovoltaic System Impacts in Distribution Networks. 2011 IEEE Power and Energy Innovative Smart Grid Technologies Asia, Perth, 13-16 November 2011, 1-8.

[2] Kabouris, J. and Kanellos, F.D. (2010) Impacts of Large-Scale Wind Penetration on Designing and Operation of Electric Power Systems. IEEE Transactions on Sustainable Energy, 1, 107-114. http://dx.doi.org/10.1109/TSTE.2010.2050348

[3] Meegahapola, L. and Flynn, D. (2010) Impact on Transient and Frequency Stability for a Power System at Very High Wind Penetration. IEEE Power and Energy Society General Meeting, Minneapolis, 25-29 July 2010, 1-8. http://dx.doi.org/10.1109/pes.2010.5589908

[4] Tarnowski, G.C., Kjær, P.C., Østergaard, J. and Sørensen, P.E. (2010) Frequency Control in Power Systems with High Wind Power Penetration. The 9th International Workshop on Large-Scale Integration of Wind Power and Transmission Networks for Offshore Wind Farms, Montreal Quebec, 18-19 October 2010.

[5] Huang, S.J. and Huang, C.C. (2010) An Automatic Load Shedding Scheme Including Pumped-Storage Units. IEEE Trans. on Energy Conversion, 15, 427-432. http://dx.doi.org/10.1109/60.900504

[6] Papaefthimiou, S., Karamanou, E., Papathanassiou, S. and Papadopoulos, M. (2009) Operating Policies for WindPumped-Storage Hybrid Power Stations in Island Grids. IET Renewable Power Generation, 3, 293-307. http://dx.doi.org/10.1049/iet-rpg.2008.0071

[7] Gjengedal, T. (2003) System Control of Large Scale Wind Power by Use of Automatic Generation Control (AGC). Quality and Security of Electric Power Delivery Systems, CIGRE/IEEE PES International Symposium, Montreal Quebec, 8-10 October 2003, 15-21. http://dx.doi.org/10.1109/qsepds.2003.159789

[8] Lee, T.Y. (2007) Optimal Spinning Reserve for a Wind-Thermal Power System Using EIPSO. IEEE Transactions on Power Systems, 22, 1612-1621. http://dx.doi.org/10.1109/TPWRS.2007.907519

[9] Liu, W.T., Wu, Y.K., Lee, C.Y. and Chen, C.R. (2011) Effect of Low-Voltage-Ride-Through Technologies on the First Taiwan Offshore Wind Farm Planning. IEEE Transactions on Sustainable Energy, 2, 78-86.

[10] Zeng, M., Zhang, K. and Wang, L. (2014) Study on Unit Commitment Problem Considering Wind Power and Pumped Hydro Energy Storage. International Journal of Electrical Power \& Energy Systems, 63, 91-96. http://dx.doi.org/10.1016/j.ijepes.2014.05.047

[11] Portero, U., Velázquez, S. and Carta, J.A. (2015) Sizing of a Wind-Hydro System Using a Reversible Hydraulic Facility with Seawater. A Case Study in the Canary Islands. Energy Conversion and Management, 106, 1251-1263. http://dx.doi.org/10.1016/j.enconman.2015.10.054

[12] Caralis, G., Rados, K. and Zervos, A. (2010) On the Market of Wind with Hydro-Pumped Storage Systems in Autonomous Greek Islands. Renewable and Sustainable Energy Reviews, 14, 2221-2226. http://dx.doi.org/10.1016/j.rser.2010.02.008 
[13] Papaefthymiou, S., Karamanou, E. and Papathanassiou, S. (2010) A Wind-Hydro-Pumped Storage Station Leading to High RES Penetration in the Autonomous Island System of Ikaria. IEEE Transactions on Sustainable Energy, 1, 163172.

[14] Dursun, B. and Alboyaci, B. (2010) The Contribution of Wind-Hydro Pumped Storage Systems in Meeting Turkey's Electric Energy Demand. Renewable and Sustainable Energy Reviews, 14, 1979-1988. http://dx.doi.org/10.1016/j.rser.2010.03.030

[15] Katsaprakakis Dimitris, A.L., Christakis Dimitris, G., Kosmas, P., Sofia, S., Irene, D., Ioannis, S., et al. (2012) Introduction of a Wind Powered Pumped Storage System in the Isolated Insular Power System of Karpathos-Kasos. Applied Energy, 97, 38-48. http://dx.doi.org/10.1016/j.apenergy.2011.11.069

[16] Anagnostopoulos, J.S. and Papantonis, D.E. (2007) Pumping Station Design for a Pumped-Storage Wind-Hydro Power Plant. Energy Conversion and Management, 48, 3009-3017. http://dx.doi.org/10.1016/j.enconman.2007.07.015

[17] Castronuovo, E.D. and Lopes, J.A.P. (2004) Optimal Operation and Hydro Storage Sizing of a Wind-Hydro Power Plant. International Journal of Electrical Power \& Energy Systems, 26, 771-778. http://dx.doi.org/10.1016/j.ijepes.2004.08.002

[18] Papaefthymiou, S.V. and Papathanassiou, S.A. (2014) Optimum Sizing of Wind-Pumped-Storage Hybrid Power Stations in Island Systems. Renewable Energy, 64, 187-196. http://dx.doi.org/10.1016/j.renene.2013.10.047

[19] Duque, A.J., Castronuovo, E.D., Sanchez, I. and Usaola, J. (2011) Optimal Operation of a Pumped-Storage Hydro Plant That Compensates the Imbalances of a Wind Power Producer. Electric Power Systems Research, 81, 1767-1777. http://dx.doi.org/10.1016/j.epsr.2011.04.008 